\title{
Effect of Acid mixtures on the Hydrolysis of Coconut Coir for Recovery of Fermentable Sugars
}

\section{*11AMENAGHAWON, NA; OSAYUKI-AGUEBOR, W; EGHAREVBA, I.P}

\author{
Department of Chemical Engineering, University of Benin \\ PMB 1154, Benin City, Nigeria \\ *E-mail:andrew.amenaghawon@uniben.edu, Phone: +234-806-9275563
}

\begin{abstract}
In this study, coconut coir was hydrolysed to produce fermentable sugars using dilute nitric and acetic acid. The hydrolysis process was carried out according to a four variable Box-Behnken design which was used to develop a statistical model to describe the relationship between the concentration of fermentable sugars produced (dependent variable) and the independent variables (time, temperature, nitric acid concentration and acetic acid concentration). Results of analysis of variance (ANOVA) performed to determine the fit of the statistical model showed that the model was statistically significant $(\mathrm{p}<0.0001)$ with a low standard deviation (1.77) and non-significant lack of fit $\left(\mathrm{R}^{2}=0.93\right)$. The concentrations of nitric and acetic acid as well as the hydrolysis time and temperature all positively influenced the hydrolysis process as evident in the increase in the amount of fermentable sugars produced when the values of these variables were increased. When both acids were combined together, the amount of fermentable sugar produced was increased by as much $54 \%$. Optimisation of the statistical model showed that the maximum sugar concentration was 32.7 $\mathrm{g} / \mathrm{L}$ and this was obtained for coconut coir catalysed by $0.50 \% \mathrm{w} / \mathrm{v}$ nitric acid, $0.40 \% \mathrm{w} / \mathrm{v}$ acetic acid at $160{ }^{\circ} \mathrm{C}$ for 30 minutes. Validation of the statistical model showed that there was no significant difference between predicted and observed values. (C) JASEM
\end{abstract}

http://dx.doi.org/10.4314/jasem/v19i3.2

KEYWORDS: Coconut coir, Lignocellulosic feedstock, Response Surface Methodology, Optimisation

The numerous environmental and energy security challenges associated with the use of conventional petroleum based liquid fuels for transportation has resulted in a rapid expansion in the market for bioethanol either as a blend with gasoline to enhance octane rating or as a primary fuel (Mohan and Reddy, 2012). Abundantly available lignocellulosic biomass has been considered as a cheap and sustainable feedstock for second generation bioethanol production (Vaithanomsat et al., 2010).

Nigeria is one of the countries that generate a substantial amount of lignocellulosic agricultural residues and wastes such as corn stover, wheat straw, cassava bagasse, sugar cane bagasse, coconut coir etc (Agbro and Ogie, 2012). Nigeria is the fifth largest producer of coconut in Africa with a net annual output of 260,000 metric tons (Uwubanmwen et al., 2011). Efforts have been made to create value from coconut wastes by utilising them as precursors for preparation of adsorbents, ropes, twines, mats, mulch for organic fertiliser etc (Anirudhan et al., 2008; Bilba et al., 2007; Namasivayam and Sangeetha, 2008). However, coconut coir has been reported to be an attractive feedstock for bioethanol production due to its high cellulose and hemicellulose content (Vaithanomsat et al., 2010). Hence more use can be found for this otherwise waste material.
The complex nature of the lignocellulose structure in coconut coir makes it necessary to take it through suitable pretreatment steps in order to recover fermentable sugars. Of all the pretreatment strategies identified in the literature, acid hydrolysis using dilute sulphuric acid is the most studied and most widely used (Satimanont et al., 2012). However, other acids such as phosphoric acid, acetic acid and nitric acid have also received some attention because these acids are less aggressive in action compared to sulphuric acid which enables them to produce a fermentable hydrolysate with lower concentration of microbial growth inhibitors such as furfural and hydroxyl methyl furfural (HMF) (Nantapipat et al., 2013).

To maximise the yield of fermentable sugars during hydrolysis, it is important to optimise the variables upon which the yield is dependent. Response surface methodology based on statistically designed experiments has been found to be very useful in optimising multivariable processes. According to Montgomery (2005), it is employed for multiple regression analysis of quantitative data obtained from statistically designed experiments. Hence, the aim of this study was to investigate the effect of combining dilute acetic and nitric acid on the hydrolysis of 
coconut coir to produce fermentable sugars. The hydrolysis process was optimised using response surface methodology to obtain maximum fermentable sugars.

\section{MATERIALS AND METHODS}

Lignocellulosic Feedstock: The coconut coir used in this study was obtained from the Faculty of Agriculture model farm in the University of Benin, Benin City, Edo State, Nigeria. It was sun dried for 24 hours to reduce moisture and prevent biodeterioration. The dried coir was milled to a particle size of about $1.5 \mathrm{~mm}$, homogenised in a single lot and stored under dry conditions prior to use. The chemical composition of coconut coir has been reported previously by Fatmawati et al. (2013).

Acid Hydrolysis: Dilute acid hydrolysis of the coconut coir was carried out in an autoclave using dilute nitric acid and acetic acid. The operating conditions of the hydrolysis process such as temperature, time and acid concentration were fixed by the experimental design. At the end of the hydrolysis process, the solid residue was separated by centrifugation and the $\mathrm{pH}$ of the resulting supernatant was adjusted to 10 using $2 \mathrm{M} \mathrm{Ca}(\mathrm{OH})_{2}$. The resulting precipitate was removed by centrifugation and the supernatant was adjusted to a $\mathrm{pH}$ of 6.5 using $10 \%$ $\mathrm{H}_{2} \mathrm{SO}_{4}$ (Amenaghawon et al., 2014a).

Analytical Methods: The fermentable sugars recovered from the coconut coir during hydrolysis were quantified by treating the hydrolysate with 3,5dinitro-salicylic acid (DNSA) which is reduced to 3amino-5-nitro-salicylic acid. The latter was quantified by measuring the absorbance at a wavelength of 540 $\mathrm{nm}$ using a UV-Vis spectrophotometer (PG Instruments model T70). The DNSA reagent consisted of $1 \mathrm{~g}$ DNS dissolved in $20 \mathrm{~mL} 2 \mathrm{M} \mathrm{NaOH}$ and $50 \mathrm{~mL}$ distilled water. Thirty grams of Rochelle salt (potassium sodium tartarate tetrahydrate: $\left.\mathrm{KO}_{2} \mathrm{CCH}(\mathrm{OH}) \mathrm{CH}(\mathrm{OH}) \mathrm{CO}_{2} \mathrm{Na} \bullet 4 \mathrm{H} 2 \mathrm{O}\right)$ was added and distilled water was added to make up the volume to $100 \mathrm{~mL}$. The reducing sugars were measured as follows: To a test tube were added the following; 0.2 $\mathrm{mL}$ reducing sugar solution, $1.8 \mathrm{~mL}$ distilled water and $2 \mathrm{~mL}$ DNSA reagent. The mixture in the test tube was boiled for $5 \mathrm{~min}$ in a water bath followed by cooling to room temperature and diluting to $24 \mathrm{~mL}$. A standard curve was prepared using known concentrations of glucose from which the concentration of reducing sugar was determined.

Experimental Design: A four variable Box-Behnken design (BBD) for response surface methodology was used to develop a statistical model for the hydrolysis process. The range of the variables that were optimised is shown in Table 1. The Box-Behnken design is suitable for the exploration of quadratic response surfaces and this design can be used to develop a second degree polynomial model which can be utilised for optimisation purposes (Amenaghawon et al., 2013). The number of experimental run for this design is obtained from Equation (1). $\quad N=k^{2}+k+c_{p}$ (1) Where $k$ is the number of factors and $c_{p}$ is the number of replications at the center point. The experimental design was developed using Design Expert ${ }^{\circledR}$ 7.0.0 (Stat-ease, Inc. Minneapolis, USA). The coded and actual values of the independent variables were calculated using Equation (2). $x_{i}=\frac{X_{i}-X_{o}}{\Delta X_{i}}$ (2) Where $x_{i}$ and $X_{i}$ are the coded and actual values of the independent variable respectively. $X_{o}$ is the actual value of the independent variable at the center point and $\Delta X_{i}$ is the step change of $X_{i}$. The following generalised second order polynomial equation was used to estimate the response of the dependent variable.

$Y_{i}=b_{o}+\sum b_{i} X_{i}+\sum b_{i j} X_{i} X_{j}+\sum b_{i i} X_{i}^{2}+e_{i}$

where $Y_{i}$ is the dependent variable or predicted response, $X_{i}$ and $X_{j}$ are the independent variables, $b_{o}$ is offset term, $b_{i}$ and $b_{i j}$ are the single and interaction effect coefficients and $e_{i}$ is the error term. The Design Expert software was used for regression and graphical analysis of the experimental data. The goodness of fit of the model was evaluated by the coefficient of determination $\left(\mathrm{R}^{2}\right)$ and analysis of variance (ANOVA). The optimum values of the variables tested were obtained by numerical optimisation based on the criterion of desirability (Jargalsaikhan and Saracoğlu, 2008).

\section{RESULTS AND DISCUSSION}

Statistical Modelling: The coefficients of the regression model were calculated using Design Expert and the following regression model was obtained.

$$
\begin{aligned}
Y= & -76.09+2.59 X_{1}-0.24 X_{2}-162.67 X_{3}-393.96 X_{4} \\
& -0.018 X_{1} X_{2}+4.55 X_{1} X_{3}-0.085 X_{1} X_{4}+2.64 X_{2} X_{4} \\
& +28.36 X_{3} X_{4}-0.032 X_{1}^{2}+109.53 X_{2}^{2}+7.54 X_{3}^{2}
\end{aligned}
$$

Table 3 shows the concentration of fermentable sugars predicted by Equation (4) alongside the experimental data. To test the fit of the statistical model, the regression equation was subjected to analysis of variance (ANOVA) and the results are presented in Tables 3 and 4. Results presented in Table 3 showed that the statistical model was highly significant as evident from the Fisher's F-test with very low probability value $(\mathrm{p}<0.0001)$. The statistical significance of the coefficients of the model was determined by $\mathrm{p}$ values as shown in Table 3 . The smaller the magnitude of the $p$ value of a term, the more significant that model term is (Tanyildizi et al., 2005). The linear terms representing the effects of time and acetic acid concentration were the most significant. Furthermore, the interactive effect of time 
and nitric acid concentration as well as temperature and acetic acid concentration were more significant than the others. Since linear and quadratic effects of time and nitric acid concentration were significant, it suggests that little variation in their levels could alter the rate of the hydrolysis process. Statistical information for ANOVA as presented in Table 4 shows that the model had a high coefficient of determination $\left(\mathrm{R}^{2}=0.93\right)$ indicating that the model explained $93 \%$ of the variability in the response. The high $\mathrm{R}^{2}$ value coupled with the low standard deviation suggests that the model showed a good fit with the experimental data and as such it was able to adequately represent the relationship between the independent variables and the response (Montgomery 2005). An adequate precision of 15.60 indicates an adequate signal for the signal-noise ratio showing that the model can be used to navigate the design space (Cao et al., 2009). Furthermore, a relatively low coefficient of variation $(\mathrm{CV}=10.89)$ suggests that the experiments were carried out with a high degree of precision (Hou and Chen, 2008). A parity plot comparing experimental and model predicted results is shown in Figure 1. The Figure shows that there was an acceptable level of fit between the experimental and model predicted results as seen in the clustering of the data points around the $45^{\circ}$ diagonal.

Optimisation of Dilute Acid Hydrolysis of Coconut Coir: The 3D response surface plots which are graphical representations of the statistical model are shown in Figures 2 to 5. The main objective of the response surface method is to efficiently search for the optimum values of the response that is being maximised. Figure 2 shows that there was an increase in the total sugar concentration released during hydrolysis when the hydrolysis time was increased. This trend is indicative of the conversion of the cellulose and hemicellulose fractions of the feedstock to fermentable sugars (Amenaghawon et al., 2014b; Palmqvist and Hahn-Hagerdal, 2000). The hydrolysis process was positively influenced by temperature as shown in Figure 2. This could be attributed to the enhancement of the rate of reaction at elevated temperatures (Najafpour et al., 2007). When the temperature was maintained below $145^{\circ} \mathrm{C}$, the sugar yield was observed to drop sharply. Hence, in order to obtain high sugar yield, the temperature should be maintained at $145-160{ }^{\circ} \mathrm{C}$. Though a positive trend was observed with respect to temperature, the implementation of high temperature hydrolysis is often discouraged as a result of the degradation of sugars to produce inhibitory products such as furfural (Palmqvist and Hahn-Hagerdal, 2000). Similar observations have been reported by previous researchers (Amenaghawon et al., 2014b; Lu and Mosier 2008; Zhang et al., 2012).

The total sugar concentration increased with increase in nitric acid concentration as shown in Figure 3. This shows that nitric acid had a significant overall positive effect on the recovery of sugars from coconut coir. Similarly, the concentration of acetic acid also had a positive influence on the hydrolysis process as shown in Figure 4. This observation could be attributed to the catalysing effect of the respective acids in cleaving the glycosidic bonds in the cellulosic material (Mosier et al., 2002). The hydrogen ions in solution are responsible for the catalytic activity of the acid. Since the catalytic activity of an acid is proportional to its hydrogen ion concentration, more hydrogen ions will be formed in solution when the concentration of the acid is increased. Consequently, the hydrolysis reaction will proceed rapidly because of the increase in the rate at which the glycosidic bonds are being cleaved to produce fermentable sugars (Kumar et al., 2009). Similar trends have been reported by previous researchers. Hu et al. (2010) investigated the acid hydrolysis of sugar maple wood extract at atmospheric pressure using dilute sulphuric acid. They observed that increasing the concentration of acid resulted in an increase in the concentration of fermentable sugars. This resulted in the conclusion that the acid acted as a catalyst in the cleavage of the $\beta$ (1-4) glycosidic linkages in the xylooligomers to yield xylose monomers. Lenihan et al. (2010) also reported that increasing the concentration of acid at mild temperatures resulted in an increase in the rate of the hydrolysis reaction.

Figure 5 shows the effect of the interaction between acetic and nitric acid concentrations on the recovery of sugars during hydrolysis. When nitric acid was used as a standalone hydrolysing agent (i.e. with $0 \% \mathrm{w} / \mathrm{v}$ acetic acid), the maximum sugar concentration recorded was about $15 \mathrm{~g} / \mathrm{L}$. When nitric acid was then combined with acetic acid, it was observed that the sugar concentration increased to a maximum of $32.7 \mathrm{~g} / \mathrm{L}$ at an acetic acid concentration of $0.4 \% \mathrm{w} / \mathrm{v}$ which corresponds to an increase of about $54 \%$. This could be attributed to an increase in the rate of xylan hydrolysis to produce fermentable sugars. From Figure 5, it is evident that the combined use of $0.5 \%(\mathrm{w} / \mathrm{v})$ of nitric acid and $0.4 \%(\mathrm{w} / \mathrm{v})$ of acetic acid is optimal for obtaining the maximum sugar yield. These results indicate that the combined use of nitric and acetic acid has a synergistic effect in improving sugar yield compared to using nitric alone (Zhang et al., 2012).

Based on the statistical model, numerical optimisation was carried out with the help of Design Expert considering each value of response and the optimisation results showed that the maximum sugar concentration of $32.7 \mathrm{~g} / \mathrm{L}$ was obtained for coconut coir catalysed by $0.50 \% \mathrm{w} / \mathrm{v}$ nitric acid, $0.40 \% \mathrm{w} / \mathrm{v}$ acetic acid at $160{ }^{\circ} \mathrm{C}$ for 30 minutes. To confirm these results, hydrolysis runs were carried out in triplicate under optimised conditions and the results indicate that there was no significant difference between 
observed and predicted values. The results obtained are similar to earlier findings by other researchers. Sun and Cheng (2005) studied the dilute $\mathrm{H}_{2} \mathrm{SO}_{4}$ (0.6$2.2 \% \mathrm{w} / \mathrm{w}$ ) hydrolysis of rye straw and Bermuda grass and found that the release of fermentable sugars was over $30 \mathrm{~g} / \mathrm{L}$ when treated with $1.5 \% \mathrm{H}_{2} \mathrm{SO}_{4}$ for $90 \mathrm{~min}$ at $121^{\circ} \mathrm{C}$. In another study, Tellez-Luis et al. (2002) investigated the dilute $\mathrm{H}_{2} \mathrm{SO}_{4}$ hydrolysis of sorghum straw and found that the release of fermentable sugar was $24.9 \mathrm{~g} / \mathrm{L}$ when treated with $2.0 \%$ $\mathrm{H}_{2} \mathrm{SO}_{4}$ for $71 \mathrm{~min}$ at $122^{\circ} \mathrm{C}$. Zhang et al. (2012) reported improvements in the yield of fermentable sugars when dilute sulphuric acid was combined with phosphoric acid to catalyse the hydrolysis of oil palm empty fruit bunch for high yield production of xylose.

Conclusion: The hydrolysis of coconut coir was catalysed using dilute nitric and acetic acid to produce fermentable sugars. The hydrolysis process was carried out according to a four variable BoxBehnken design and the process was optimised using response surface. Increasing the hydrolysis time had an overall positive effect on the hydrolysis process. The same trend was observed for temperature as well as the concentration of nitric and acetic acid. When applied individually, both acids positively influence the recovery of fermentable sugars from coconut coir. When combined together, the amount of fermentable sugar produced was increased by as much 54\%. The maximum sugar concentration of $32.7 \mathrm{~g} / \mathrm{L}$ was obtained for coconut coir catalysed by $0.50 \% \mathrm{w} / \mathrm{v}$ nitric acid, $0.40 \% \mathrm{w} / \mathrm{v}$ acetic acid at $160{ }^{\circ} \mathrm{C}$ for 30 minutes.

Table 1: Experimental range and levels of independent variables

\begin{tabular}{lcccc}
\hline \multicolumn{1}{c}{ Independent Variables } & Symbols & \multicolumn{3}{c}{ Coded and actual levels } \\
\cline { 3 - 5 } & & -1 & 0 & +1 \\
Time $(\min )$ & $\mathrm{X}_{1}$ & 10 & 20 & 30 \\
Temperature $\left({ }^{\circ} \mathrm{C}\right)$ & $\mathrm{X}_{2}$ & 140 & 150 & 160 \\
Nitric acid conc. $(\% \mathrm{w} / \mathrm{v})$ & $\mathrm{X}_{3}$ & 0.25 & 0.38 & 0.5 \\
Acetic acid conc. $(\% \mathrm{w} / \mathrm{v})$ & $\mathrm{X}_{4}$ & 0 & 0.2 & 0.4 \\
\hline
\end{tabular}

\begin{tabular}{|c|c|c|c|c|c|c|c|c|c|c|}
\hline \multirow{3}{*}{$\begin{array}{c}\text { Run } \\
\text { No }\end{array}$} & \multicolumn{8}{|c|}{ Factors } & \multicolumn{2}{|c|}{ Response } \\
\hline & \multicolumn{4}{|c|}{ Coded levels } & \multicolumn{4}{|c|}{ Actual values } & \multicolumn{2}{|c|}{ Total sugar conc. $(\mathrm{g} / \mathrm{L})$} \\
\hline & $\mathrm{X}_{1}$ & $\mathrm{X}_{2}$ & $\mathrm{X}_{3}$ & $\mathrm{X}_{4}$ & $\mathrm{X}_{1}$ & $\mathrm{X}_{2}$ & $\mathrm{X}_{3}$ & $\mathrm{X}_{4}$ & Observed & Predicted \\
\hline $\mathbf{1}$ & 0 & 0 & 1 & -1 & 20 & 150 & 0.50 & 0.0 & 20.16 & 20.44 \\
\hline 2 & 0 & 1 & 0 & 1 & 20 & 160 & 0.38 & 0.4 & 17.45 & 15.66 \\
\hline 3 & -1 & 0 & -1 & 0 & 10 & 150 & 0.25 & 0.2 & 13.37 & 12.95 \\
\hline 4 & -1 & 0 & 0 & 1 & 10 & 150 & 0.38 & 0.4 & 14.16 & 14.54 \\
\hline 5 & 0 & 0 & 1 & 1 & 20 & 150 & 0.50 & 0.4 & 15.75 & 15.66 \\
\hline 6 & 1 & 1 & 0 & 0 & 30 & 160 & 0.38 & 0.2 & 8.24 & 6.85 \\
\hline 7 & -1 & -1 & 0 & 0 & 10 & 140 & 0.38 & 0.2 & 14.00 & 15.66 \\
\hline 8 & 0 & -1 & -1 & 0 & 20 & 140 & 0.25 & 0.2 & 5.63 & 5.98 \\
\hline 9 & -1 & 0 & 1 & 0 & 10 & 150 & 0.50 & 0.2 & 8.56 & 8.17 \\
\hline 10 & 0 & 0 & 0 & 0 & 20 & 150 & 0.38 & 0.2 & 14.00 & 15.66 \\
\hline 11 & 0 & 0 & -1 & 1 & 20 & 150 & 0.25 & 0.4 & 15.46 & 15.61 \\
\hline 12 & 1 & 0 & -1 & 0 & 30 & 150 & 0.25 & 0.2 & 14.71 & 13.58 \\
\hline 13 & -1 & 0 & 0 & -1 & 10 & 150 & 0.38 & 0.0 & 15.32 & 14.23 \\
\hline 14 & -1 & 1 & 0 & 0 & 10 & 160 & 0.38 & 0.2 & 15.99 & 15.68 \\
\hline 15 & 0 & -1 & 0 & 1 & 20 & 140 & 0.38 & 0.4 & 17.53 & 15.66 \\
\hline 16 & 0 & 0 & 0 & 0 & 20 & 150 & 0.38 & 0.2 & 17.08 & 18.25 \\
\hline 17 & 1 & 0 & 0 & 1 & 30 & 150 & 0.38 & 0.4 & 11.95 & 12.84 \\
\hline 18 & 0 & -1 & 0 & -1 & 20 & 140 & 0.38 & 0.0 & 15.62 & 15.70 \\
\hline 19 & 0 & -1 & 1 & 0 & 20 & 140 & 0.50 & 0.2 & 15.62 & 17.08 \\
\hline 20 & 0 & 0 & 0 & 0 & 20 & 150 & 0.38 & 0.2 & 20.05 & 19.10 \\
\hline 21 & 1 & 0 & 0 & -1 & 30 & 150 & 0.38 & 0.0 & 4.79 & 4.48 \\
\hline 22 & 1 & 0 & 1 & 0 & 30 & 150 & 0.50 & 0.2 & 22.84 & 21.66 \\
\hline 23 & 0 & 0 & 0 & 0 & 20 & 150 & 0.38 & 0.2 & 12.24 & 13.72 \\
\hline 24 & 0 & 0 & -1 & -1 & 20 & 150 & 0.25 & 0.0 & 20.99 & 19.68 \\
\hline 25 & 0 & 1 & -1 & 0 & 20 & 160 & 0.25 & 0.2 & 11.08 & 10.73 \\
\hline 26 & 0 & 1 & 0 & -1 & 20 & 160 & 0.38 & 0.0 & 11.92 & 12.23 \\
\hline 27 & 1 & -1 & 0 & 0 & 30 & 140 & 0.38 & 0.2 & 8.46 & 9.86 \\
\hline 28 & 0 & 1 & 1 & 0 & 20 & 160 & 0.50 & 0.2 & 16.04 & 17.10 \\
\hline 29 & 0 & 0 & 0 & 0 & 20 & 150 & 0.38 & 0.2 & 17.42 & 17.71 \\
\hline
\end{tabular}


Table 3: Analysis of variance for statistical model

\begin{tabular}{|c|c|c|c|c|c|c|c|}
\hline Sources & $\begin{array}{l}\text { Sum of } \\
\text { Squares }\end{array}$ & df & $\begin{array}{l}\text { Mean } \\
\text { Squares }\end{array}$ & F value & p value & \multicolumn{2}{|c|}{$\begin{array}{c}\text { Table 4: Statistical information for } \\
\text { ANOVA }\end{array}$} \\
\hline Model & 641.48 & 12 & 53.46 & 16.99 & $<0.0001$ & Parameter & Response Value \\
\hline $\mathbf{X}_{1}$ & 115.58 & 1 & 115.58 & 36.74 & $<0.0001$ & & 0.93 \\
\hline $\mathbf{X}_{2}$ & 5.64 & 1 & 5.64 & 1.79 & 0.1995 & Adjusted $R^{2}$ & 0.87 \\
\hline $\mathbf{X}_{3}$ & 49.13 & 1 & 49.13 & 15.62 & 0.0011 & Mean & 16.29 \\
\hline $\mathbf{X}_{4}$ & 110.23 & 1 & 110.23 & 35.04 & $<0.0001$ & Standard & 1.77 \\
\hline $\mathbf{X}_{1} \mathbf{X}_{2}$ & 12.95 & 1 & 12.95 & 4.12 & 0.0595 & CV \% & 10.89 \\
\hline $\mathbf{X}_{1} \mathbf{X}_{3}$ & 129.52 & 1 & 129.52 & 41.17 & $<0.0001$ & Adeq. Precision & 15.60 \\
\hline $\mathbf{X}_{1} \mathbf{X}_{4}$ & 0.11 & 1 & 0.11 & 0.036 & 0.8512 & & \\
\hline $\mathbf{X}_{2} \mathbf{X}_{4}$ & 112.17 & 1 & 112.17 & 35.65 & $<0.0001$ & & \\
\hline $\mathbf{X}_{3} \mathbf{X}_{4}$ & 2.01 & 1 & 2.01 & 0.64 & 0.4358 & & \\
\hline $\mathrm{X}_{1}^{2}$ & 68.39 & 1 & 68.39 & 21.74 & 0.0003 & & \\
\hline $\mathbf{X}_{3}{ }^{2}$ & 19.70 & 1 & 19.70 & 6.26 & 0.0236 & & \\
\hline $\mathbf{X}_{4}^{2}$ & 0.61 & 1 & 0.61 & 0.19 & 0.6653 & & \\
\hline Residual & 50.34 & 16 & 3.15 & & & & \\
\hline Lack of Fit & 40.41 & 12 & 3.37 & 1.36 & 0.4157 & & \\
\hline Pure Error & 9.93 & 4 & 2.48 & & & & \\
\hline Cor Total & 691.81 & 28 & & & & & \\
\hline
\end{tabular}

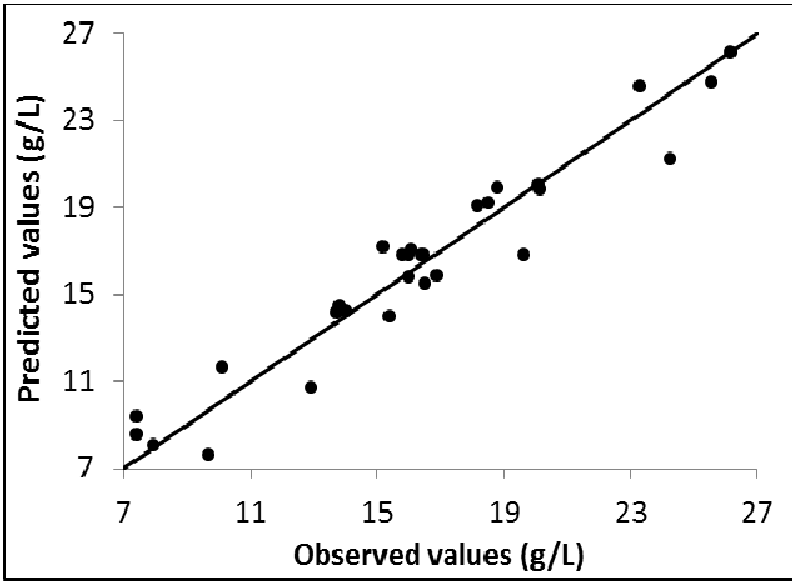

Fig 1: Parity plot showing comparison between experimental and predicted values

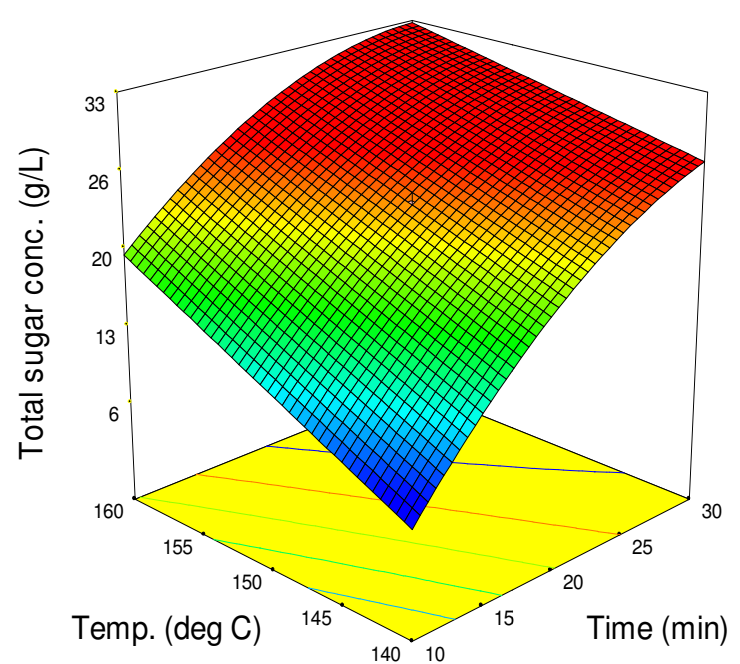

Fig 2: Effect of time and temperature on total sugar concentration

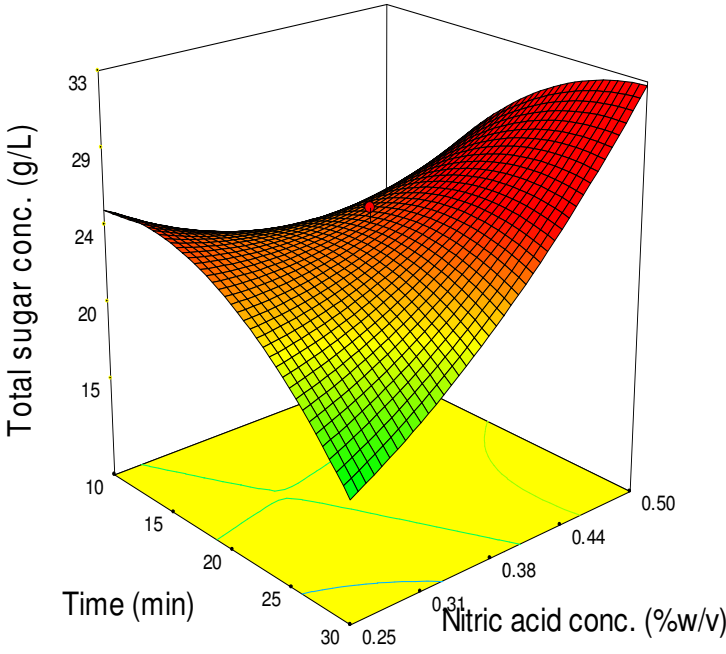

Fig 3: Effect of time and nitric acid concentration on total sugar concentration 


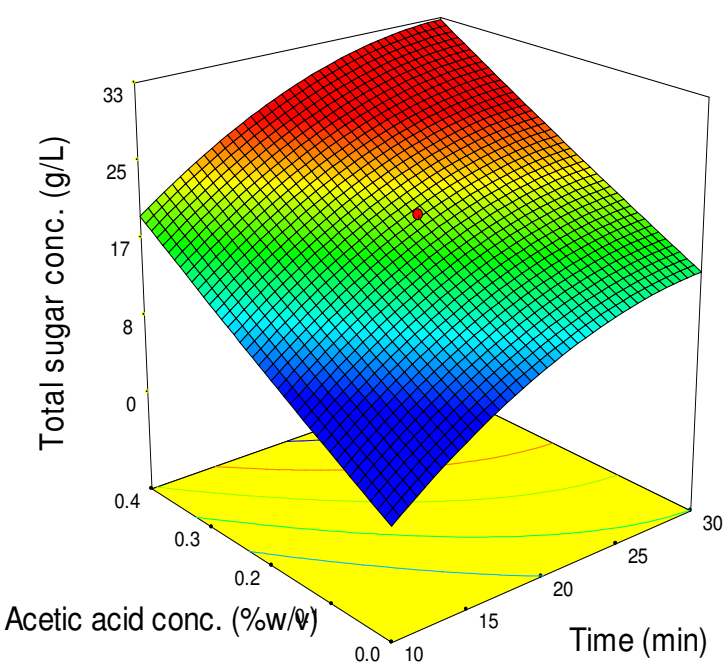

Fig 4: Effect of time and acetic acid concentration on total sugar concentration

\section{REFERENCES}

Agbro, E.B.; and Ogie, N.A. (2012) A Comprehensive Review of Biomass Resources and Biofuel Production Potential in Nigeria. Research Journal in Engineering and Applied Sciences, 1(3): 149-155.

Amenaghawon, N.A.; Nwaru, K.I.; Aisien, F.A.; Ogbeide, S.E.; Okieimen, C.O. (2013b). Application of Box-Behnken Design for the Optimization of Citric Acid Production from Corn Starch Using Aspergillus niger. British Biotechnology Journal, 3(3): 236-245.

Amenaghawon, N.A.; Ogbeide, S.E.; Okieimen, C.O. (2014a). Application of Statistical Experimental Design for the Optimisation of Dilute Sulphuric Acid Hydrolysis of Cassava Bagasse. Acta Polytechnica Hungarica, 11(9): 239-250.

Amenaghawon, N.A.; Ogbeide, S.E.; Okieimen, C.O. (2014b). Optimisation of lime pretreatment of corn stover using response surface methodology. Journal of the Nigerian Association of Mathematical Physics, 28(1): 499-504.

Anirudhan, T.S.; Divya, L.; and Ramachandran, M. (2008). Mercury (II) removal from aqueous solutions and wastewaters using a novel cation exchanger derived from coconut coir pith and its recovery. Journal of Hazardous Materials, 157: 620-627.

Bilba, K., Arsene, M.A. and Ouensanga, A. (2007). Study of banana and coconut fibers: Botanical composition, thermal degradation and textural observations. Bioresource Technology 98: 58-68.

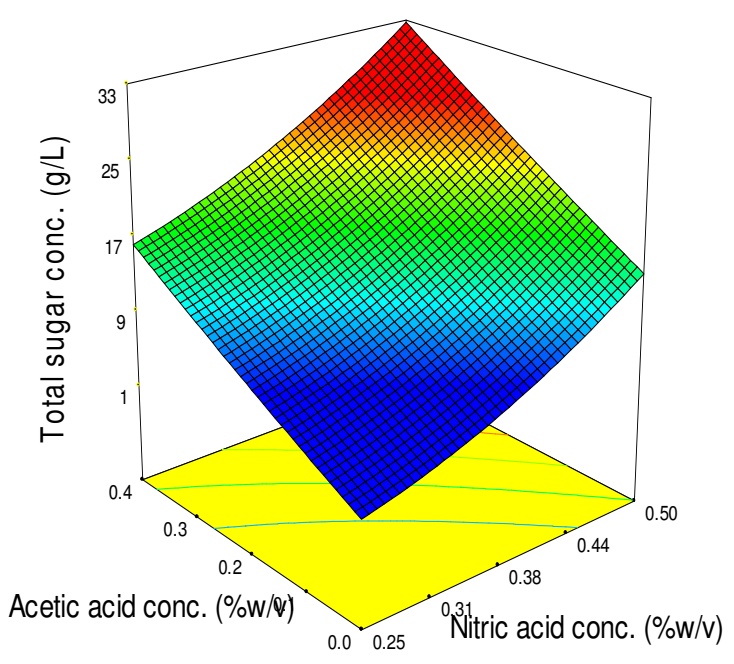

Fig 5: Effect of acetic and nitric acid concentration on total sugar concentration

Cao, G.; Ren, N.; Wang, A.; Lee, D.J.; Guo, W.; Liu, B.; Feng, Y.; Zhao, Q. (2009). Acid hydrolysis of corn stover for biohydrogen production using Thermoanaerobacterium thermosaccharolyticum W16. International Journal of Hydrogen Energy, 34: 7182-7188.

Fatmawati, A., Agustriyanto, R. and Liasari, Y. (2013). Enzymatic Hydrolysis of Alkaline Pretreated Coconut Coir. Bulletin of Chemical Reaction Engineering \& Catalysis, 8(1): 34-39.

Hou, X.J.; Chen, W. (2008). Optimization of extraction process of crude polysaccharides from wild edible Bachu mushroom by response surface methodology. Carbohydrate Polymers, 72: 67-74.

Hu, R.; Lin, L.; Liu, T.; Liu, S. (2010). Dilute sulphuric acid hydrolysis of sugar maple wood extract at atmospheric pressure. Bioresource Technology 101(10): 3586-3594.

Jargalsaikhan, O.; and Saracoğlu, N. (2008). Application of experimental design method for ethanol production by fermentation of sunflower seed hull hydrolysate using Pichia stipitis NRRL-124. Chemical Engineering Communications, 196(1-2): 93-103.

Kim, B.J.; Hsieh, H.N.; Tai, F.J. (1999) Anaerobic digestion and acid hydrolysis of nitrocellulose, CERL Technical Report 99/45, US Army Corps of Engineers, Construction Engineering Research Laboratories. http://dx.doi.org/10.1016/j.renene.2012.08.032

Kumar, P.; Barrett, D.M.; Delwiche, M.J.; Stroeve, P. (2009). Methods for pretreatment of 
lignocellulosic biomass for efficient hydrolysis and biofuel production. Industrial and Engineering Chemistry Research, 48: 3713-3729

Lenihan, P.; Orozco, A.; O'neill, E.; Ahmad, M.N.M.; Rooney, D.W.; Walker, G.M. (2010). Dilute acid hydrolysis of lignocellulosic biomass. Chemical Engineering Journal 156(2): 395-403.

Lu, Y.; Mosier, N.S. (2008). Kinetic modeling analysis of maleic acid-catalyzed hemicellulose hydrolysis in corn stover. Biotechnology and Bioengineering, 101: 1170-1181.

Miller, G.L. (1959). Use of Dinitrosalicylic Acid Reagent for Determination of Reducing Sugar. Analytical Chemistry, 31(3): 426-428.

Mohan, P.R.; Reddy, O.V.S. (2012). Production and Optimisation of Ethanol from Pretreated Sugarcane Bagasse using Saccharomyces bayanus in Simultaneous Saccharification and Fermentation. Microbiology Journal, 2(2): 52-63.

Montgomery, D.C. (2005). Design and Analysis of experiments 6th ed., New York: John Wiley \& Sons, Inc.

Mosier, N.S.; Ladisch, C.M.; Ladich, M.R. (2002). Characterization of acid catalytic domains for cellulose hydrolysis and glucose degradation. Biotechnology and Bioengineering, 6(79): 610618.

Namasivayam, C.; Sangeetha, D. (2008). Application of coconut coir pith for the removal of sulfate and other anions from water. Desalination, 219: $1-13$.

Nantapipat, J.; Luengnaruemichai, A.; Wongkasemjit, S. (2013). A Comparison of Dilute Sulfuric and Phosphoric Acid Pretreatments in Biofuel Production from Corncobs. World Academy of Science, Engineering and Technology, 7: 477481.

Najafpour, G.; Ideris, A.; Salmanpour, S.; Norouzi, M. (2007). Acid hydrolysis of pretreated palm oil lignocellulosic wastes. IJE Transactions, 20: $147-156$.
Palmqvist, E.; Hahn-Hagerdal, B. (2000).

Fermentation of lignocellulosic hydrolysates. II: Inhibitors and mechanisms of inhibition. Bioresource Technology, 74: 25-33.

Satimanont, S.; Luengnaruemitchai, A.;

Wongkasemjit, S. (2012). Effect of temperature and time on dilute acid pretreatment of corn cobs. International Journal Chemical Biological Engineering, 6: 333-337.

Sun Y.; Cheng J.J. (2005). Dilute acid pretreatment of rye straw and Bermuda grass for ethanol production. Bioresource Technology, 96: 15991606.

Tanyildizi, M.S.; Ozer, D.; Elibol, M. (2005). Optimization of a-amylase production by Bacillus sp. using response surface methodology. Process Biochemistry, 40: 2291-2296.

Tellez-Luis, S.J.; Ramirez, J.A.; Vazques, M. (2002). Mathematical modeling of hemicellulosic sugar production from sorghum straw. Journal of Food Engineering, 52: 285-291.

Uwubanmwen, I.O.; Nwawe, C.N.; Okere, R.A.; Dada, M.; Eseigbe, E. (2011). Harnessing the Potentials of the Coconut Palm in the Nigerian Economy. World Journal of Agricultural Sciences, 7(6): 684-691.

Vaithanomsat, P.; Apiwatanapiwat, W.; Chumchuent, N.; Kongtud, W. and Sundhrarajun, S. (2010). Possibility of ethanol production from coconut husk using separate hydrolysis and fermentation and simultaneous saccharification and fermantation. In: Proceedings of the 48th Kasetsart University Annual Conference, Kasetsart, 3-5 March, 2010. Subject: Natural Resources and Environment. Kasetsart University.

Zhang, D.; Ong, Y.L.; Li, Z., Wu, J.C. (2012). Optimisation of dilute acid-catalysed hydrolysis of oil palm empty fruit bunch for high yieldproduction of xylose. Chemical Engineering Journal, 181; 636-642. 